\title{
Predictors of antibiotic prescriptions: a knowledge, attitude and practice survey among physicians in tertiary hospitals in Nigeria
}

Dimie Ogoina ( $\nabla$ dimieogoina@gmail.com )

Niger Delta University https://orcid.org/0000-0002-2098-6300

Garba lliyasu

Aminu Kano Teaching Hospital

Vivian Kwaghe

University of Abuja Teaching Hospital

Akan Otu

University of Calabar

Iorhen Ephram Akase

Lagos University Teaching Hospital

Olukemi Adekanmbi

University of Ibadan

Mahmmod Dalhat

Nigeria Centre for Disease Control

Micheal Iroezindu

University of Nigeria Teaching Hospital

Shamsudin Aliyu

Ahmadu Bello University Teaching Hospital

Abisoye Sunday Oyeyemi

Niger Delta University

Stella Rotifa

Federal Medical Center Yenagoa

Mukhtar Abdulmajid Adeiza

Ahmadu Bello University Teaching Hospital

Uche Sonny Unigwe

University of Nigeria Teaching Hospital

Juliet ljeoma Mmerem

University of Nigeria Teaching Hospital

Farouq Muhammad Dayyab

Infectious Disease Hospital, Kano

Zaiyad Garba Habib

University of Abuja Teaching Hospital

Daniel Otokpa

University of Calabar

Emmanuel Effa

University of Calabar

Abdulrazaq Garba Habib

Aminu Kano Teaching Hospital

\section{Research Article}

Keywords: Antimicrobial resistance, KAP, Antibiotic prescriptions, Antimicrobial stewardship, Nigeria

Posted Date: February 18th, 2021

DOI: https://doi.org/10.21203/rs.3.rs-206230/v1

License: @ (1) This work is licensed under a Creative Commons Attribution 4.0 International License. Read Full License 


\section{Abstract}

\section{Background}

As part of the Global Action Plan against antimicrobial resistance (AMR), countries are required to generate local evidence to inform context-specific implementation of national action plans against AMR (NAPAR). We aimed to evaluate the knowledge, attitude, and practice (KAP) regarding antibiotic prescriptions (APR) and AMR among physicians in tertiary hospitals in Nigeria, and to determine predictors of KAP of APR and AMR.

\section{Methods}

In this cross-sectional study, we enrolled physicians practicing in tertiary hospitals from all six geopolitical zones of Nigeria. Implementation of an antimicrobial stewardship programmes (ASP) by each selected hospital were assessed using a 12 item ASP checklist. We used a structured self-administered questionnaire to assess the KAP of APR and AMR. Frequency of prescriptions of 18 different antibiotics in the prior six months was assessed using a Likert's scale. KAP and prescription ( $\mathrm{Pr}$ ) scores were classified as good (score $\geq 80 \%$ ) or average/poor (score $<80 \%$ ). Independent predictors of good knowledge, attitude, and practice (KAPPr) were ascertained using an unconditional logistic regression model.

\section{Results}

A total of 1324 physicians out of 1778 ( $74 \%$ response rate) practicing in 12 tertiary hospitals in 11 states across all six geopolitical zones participated in the study. None of the participating hospitals had a formal ASP programme and majority did not implement antimicrobial stewardship strategies. The median KAPPr scores were $71.1 \%, 77 \%, 75 \%$ and $53.3 \%$, for the knowledge, attitude, practice, and prescription components, respectively. Only $22.3 \%$, $40.3 \%, 31.6 \%$ and $31.7 \%$ of study respondents had good KAPPr, respectively. All respondents had prescribed one or more antibiotics in the prior six months, mostly Amoxicillinclavulanate (98\%), fluoroquinolones (97\%), and ceftriaxone (96.8\%). About $68 \%$ of respondents had prescribed antibiotics from the World Health Organization (WHO) reserve group. Prior AMR training, professional rank, department, and hospital of practice were independently associated with good KAPPr.

\section{Conclusions}

Our study suggests gaps in knowledge and attitude of APR and AMR with inappropriate prescriptions of antibiotics among physicians practicing in tertiary hospitals in Nigeria. Nigeria's NAPAR should also target establishment and improvement of ASP in hospitals and address institutional, educational, and professional factors that may influence emergence of AMR in Nigeria.

\section{Introduction}

The discovery of antibiotics has completely revolutionized medical practice and led to a decrease in the morbidity and mortality due to infectious diseases across the globe.[1] However, microbial evolution, misuse of antibiotics, and poor infection control practices, among other factors, have led to global emergence of antimicrobial resistance organisms (AMRO) with attendant difficult-to-treat infections, prolonged hospital stay, higher healthcare costs and poorer health outcomes. [2,3]

While the threat of antimicrobial resistance (AMR) remains a growing global challenge, developing countries in Asia and Africa are at greatest risk. It is estimated that by 2050 , if nothing is done to halt the increasing trend of AMR, about 10 million people will die from AMR globally, including about 4 million people each from Asia and Africa.[4] At the 68th World Health Assembly, which held in May 2015, member countries endorsed a Global Action Plan (GAP) against AMR.[5] This plan required all countries to develop and implement a National Action Plan for Antimicrobial Resistance (NAPAR). The World Health Organization (WHO) is advocating that member countries adopt and implement the revised Model List of Essential Medicines which grouped antibiotics into the Access, Watch and Reserve (AWaRe) categories.[6] The Access group comprises essential antibiotics that should always be available. The Watch group consists of critically important antibiotics recommended only for specific limited indications, while the Reserve group are antibiotics that should be used as last resort when others have failed. [6] The AWaRe classification is intended to improve access to lifesaving antimicrobial medicines and prevent resistance due to excessive use of some priority antibiotics.

Nigeria has a high burden of infectious diseases (ID) and these are the commonest cause of disease mortality in the country.[7] Following a country-wide situational analysis of antimicrobial use and resistance, Nigeria has identified AMR as an emerging health challenge deserving broad, good quality and locally relevant data to inform evidence-based interventions.[8] The focus areas of Nigeria's five-year (2017-2022) NAPAR are to: improve awareness and understanding of AMR and related topics; strengthen One Health AMR surveillance and research; improve infection prevention and control in tripartite sector; promote rational access to antibiotics and antimicrobial stewardship; and invest in AMR-related research and development.[9]

Several studies within and outside Nigeria have shown that AMRO occur commonly among patients admitted in intensive care units, paediatric units and other specialist units often situated within tertiary hospitals.[10,11] The major drivers of AMR in these settings are heavy antibiotic use and cross infection from hospital environment or personnel.[12] Tertiary hospitals are therefore potential breeding ground for the development and spread of AMRO in Nigeria.

Implementation of antimicrobial stewardship programmes (ASP) lies at the core of optimizing appropriate use of antibiotics in healthcare facilities.[13,14] Any strategy to improve awareness and understanding of AMR and optimize the use of antibiotics among healthcare facilities in Nigeria, should evaluate implementation of ASP and ASM-related strategies among tertiary hospitals, and identify gaps in knowledge, attitude and practices (KAP) regarding antibiotic prescriptions (APR) and AMR among physicians.

Previous studies have shown that only $13 \%$ to $35 \%$ of tertiary hospitals in Nigeria had a formal ASP and majority did not implement most ASM-related strategies.[15,16] Other studies conducted among physicians in tertiary hospitals in from revealed gaps in knowledge of AMR and poor practice of APR.[17,18] 
However, none of these studies included participants from all six geopolitical zones of Nigeria and none assessed the predictors of appropriate KAP of APR and AMR among physicians in Nigeria.

We aimed to determine the KAP of APR and AMR, and identify sociodemographic, educational, institutional, and professional factors that may be associated with good KAP of APR and AMR among physicians in tertiary hospitals across all six geopolitical zones of Nigeria. Our overarching goal was to generate valuable national data to inform implementation of the country's NAPAR.

\section{Methods}

\section{Study design}

This cross-sectional study was conducted between October 2018 and February 2019 among physicians practicing in public tertiary hospitals in Nigeria.

\section{Study population and setting}

Nigeria runs a federal system of government consisting of a Federal Government, 36 semi-autonomous State Governments, the Federal Capital Territory (FCT) and 774 Local Government Areas. The states and FCT are grouped into six geo-political zones: South-South, South-East, South-West, North-East, North-West, and North Central. There are 101 public tertiary health facilities across all the 36 states and the FCT of Nigeria.[19] These public tertiary hospitals include federal and state-owned teaching hospitals, Federal Medical Centres and specialist hospitals. In Nigeria, tertiary hospitals provide both comprehensive and specialists healthcare to the general population; they are also centres for postgraduate medical training and health research.

\section{Study participants}

We selected 12 tertiary hospitals across the country by convenience sampling and included at least one hospital from each of the six geopolitical zones of the country. In a bid to generate representative data, and allow for appropriate sub-group analysis, we targeted at least $40 \%$ of physicians working in each hospital. We then adopted a purposive sampling technique to guarantee inclusion of physicians of all professional ranks and departments in each of the selected hospitals. There were 4446 physicians in all 12 hospitals at the time of the study, and 1778 (40\%) were eligible to be enrolled for the study.

\section{Data collection}

A structured standardized self-administered pretested questionnaire was distributed to the study participants by trained research assistants who ensured that all completed questionnaires were returned the same day.

The questionnaire consisted of questions divided into four sections: (1) Implementation of antibiotic stewardship programmes (ASP) in selected hospitals and prior training on APR and AMR (2) Demographic and occupational characteristics of study participants; (3) Knowledge, attitude and practice of antibiotic prescriptions and resistance. (4) Frequency of prescriptions of 18 different antibiotics in the six months prior to the study.

The questionnaire was developed after reviewing qualitative and quantitative literatures for relevant items,[20,21] including prior surveys by the WHO.[14,22] The questionnaire was further reviewed for face and content validity by experts in the field of ID and public health. This was then pre-tested in three states in a sample of 30 physicians who were not part of the study. Necessary adjustments were made before sending out the final updated questionnaires to respondents. The validity of the KAP questionnaire was confirmed by a Cronbach's alpha internal consistency coefficient of $\geq 0.75$ for each the 3 components.

\section{Implementation of antimicrobial stewardship programmes}

A checklist consisting of 12 items assessed compliance with elements of ASP (see figure 2). The checklist was completed by appropriate staff as designated by the hospital management, including focal person on ASP or lead IPC team or Head Pharmacy unit, whichever is applicable.

A correct response to each ASP question was scored 1 while incorrect responses were scored 0 . Thus, ASP scores range from 0 to 12

\section{Knowledge, attitude, and practice}

Participants' knowledge of APR and AMR was assessed by a set of 28 questions covering general awareness about antibiotic use and resistance (eight questions), knowledge of rational use of antibiotics (eight questions), definition of AMR (one question) and knowledge of causes of antimicrobial resistance (11 questions). Correct responses were scored 1 while each wrong or do not know answer was scored 0 . The overall knowledge score ranged from 0 to 28.

Attitude was assessed by a set of 15 positive and negative attitude questions using a five-point Likert's scale. The scoring system used for positive attitude was: $5=$ strongly agree with the statement, $4=$ agree, $3=$ neutral, $2=$ disagree and $1=$ strongly disagree with the statement. The scores were reversed for negative attitude questions. Overall attitude scores ranged from 15 to 75.

Practice was assessed by a set of 13 positive and negative practice questions using a five-point Likert's scale. The scoring system used for correct practice was: 5 = Always, 4 = Most Often, 3 = Sometimes, 2 = Rarely and 1 = Never. The scores were reversed for wrong practice questions. Overall practice scores ranged from 13 to 65 .

\section{Frequency of antibiotic prescriptions}

To determine the frequency of prescriptions of 18 different antibiotics, respondents were asked to indicate how many times they prescribed each antibiotic in the previous six months using a Likert's scale of Never, Rarely, Sometimes, Most Often, Always, scored 1,2,3,4 and 5 respectively. Overall prescription scores 
ranged from 18 to 90 .

\section{Classification of ASP, KAP and prescription scores}

We calculated percentage scores for each ASP, KAP and prescription score. The 18 antibiotics were further classified into the WHO AWaRe categories.[6] At the time of this study, Cefepime was classified as a Reserve antibiotic. Prior prescriptions of the AWaRe categories of antibiotics were expressed in percentages.

Using modified Bloom's cut-off point,[23] the percentage ASP/KAP scores were grouped into good ASP/KAP (scores were between 80 and $100 \%$ ), average ASP/KAP (scores between 50\% and 79\%) and poor ASP/KAP (scores less than 50\%). The percentage prescription scores were also categorized into three groups: poor/very frequent prescriptions (scores were between 80 and 100\%), average /moderately frequent prescription (prescription score between 50 and $100 \%$ ) and good/less frequent prescription (prescription score less than $50 \%$ ).

\section{Statistical analysis}

The collected data were checked for completeness and errors before analysis. Incomplete questionnaires were excluded and counted as a non-response. All completed questionnaires were then entered into Microsoft Excel and exported to SPSS version 20 for analysis.

Study variables were summarized using frequencies, proportions, medians, and interquartile range-IQR (quantitative variables were not normally distributed). Spearman rho's correlation coefficient was used to describe the strength and direction of the relationship among KAPPr scores. Correlations were interpreted using the following criteria: $0-0.25=$ weak correlation, $0.25-0.5=$ fair correlation, $0.5-0.75=$ good correlation and greater than $0.75=$ excellent correlation. A chi-squared test was used for bivariate analysis. For multivariate analysis, KAPPr scores were grouped into two: Good KAPPr (scores $\geq 80 \%$ ) and Average/Poor KAPPr (scores $<80 \%$ ). An unconditional binary logistic regression was used to determine independent variables associated with good KAPPr. Adjusted odds ratio with $95 \%$ confidence level were computed, and p-value $<0.05$ (two-sided) was considered statistically significant.

\section{Ethical consideration}

All potential participants who agreed to participate provided written consent before completion of questionnaire. The questionnaire was anonymized, and confidentiality of information obtained was maintained. Ethical approval for the study was obtained from National Health Research Ethics Committee (NHREC/01/01/2017).

\section{Results}

\section{Sociodemographic data}

Of 1778 questionnaires, 1324 ( $74 \%$ response rate) were completed and returned from 11 states and 12 hospitals across all geopolitical zones of Nigeria (Figure 1). Of the 1324 respondents, 889 (67.3\%) were males, 1003 (75.6\%) were between age 25 and 39 years and $834(63 \%)$ were of the residency professional cadre. The south-south $(26.9 \%)$ and the north-west $(25.8 \%)$ regions had the highest proportions of respondents (Table 1$)$.

Table 1: Demographic Characteristics and Professional features of Respondents 


\begin{tabular}{|c|c|c|c|}
\hline Characteristics & Frequency & $(N=1324)$ & Percent (\%) \\
\hline \multicolumn{4}{|l|}{ Sex } \\
\hline Male & 891 & & 67.3 \\
\hline Female & 433 & & 32.7 \\
\hline \multicolumn{4}{|l|}{ Age group } \\
\hline $15-24 y r s$ & 39 & & 2.9 \\
\hline $25-39 y r s$ & 1003 & & 75.8 \\
\hline $40-59 y r s$ & 264 & & 19.9 \\
\hline Over 59yrs & 18 & & 1.4 \\
\hline \multicolumn{4}{|l|}{ Department } \\
\hline Emergency unit & 35 & & 2.7 \\
\hline Family medicine & 81 & & 6.1 \\
\hline Internal medicine & 259 & & 19.6 \\
\hline Obstetrics \& Gynaecology & 514 & & 38.8 \\
\hline Paediatrics & 132 & & 10.0 \\
\hline Public health & 37 & & 2.8 \\
\hline Surgery & 163 & & 12.3 \\
\hline Others & 103 & & 7.8 \\
\hline \multicolumn{4}{|l|}{ Professional Cadre } \\
\hline House officer & 268 & & 20.2 \\
\hline Medical officer & 45 & & 3.4 \\
\hline Resident & 834 & & 63.0 \\
\hline Consultant & 177 & & 13.4 \\
\hline \multicolumn{4}{|l|}{ Prior Training on AMR } \\
\hline Yes & 417 & & 31.5 \\
\hline No & 907 & & 68.5 \\
\hline \multicolumn{4}{|l|}{ Region and Health Facility } \\
\hline \multicolumn{4}{|l|}{ North-central } \\
\hline UATH & 98 & & 7.4 \\
\hline \multicolumn{4}{|l|}{ North-east } \\
\hline FMCN & 38 & & 2.9 \\
\hline \multicolumn{4}{|l|}{ North-west } \\
\hline ABUTH & 235 & & 17.7 \\
\hline AKTH & 107 & & 8.1 \\
\hline FMCBK & 43 & & 3.2 \\
\hline \multicolumn{4}{|l|}{ South-east } \\
\hline UNTH & 88 & & 6.6 \\
\hline FMCO & 136 & & 10.3 \\
\hline \multicolumn{4}{|l|}{ South-south } \\
\hline NDUTH & 109 & & 8.2 \\
\hline UCTH & 164 & & 12.4 \\
\hline FMCY & 83 & & 6.3 \\
\hline \multicolumn{4}{|l|}{ South-west } \\
\hline $\mathrm{UCH}$ & 100 & & 7.6 \\
\hline
\end{tabular}

Page 5/21 
Abbreviation: UNTH-University of Nigeria Teaching Hospital, Enugu; AKTH- Aminu Kano University Teaching Hospital, Kano; NDUTH-Niger Delta University Teaching Hospital, Bayelsa; UCH-University College Hospital, Oyo State; LUTH-Lagos University Teaching Hospital, Lagos; UCTH-University of Calabar Teaching Hospital; UATH-University of Abuja Teaching Hospital

\section{Implementation of Antimicrobial stewardship among hospitals and AMR training}

Out of a possible total score of 12, the ASP scores of hospitals surveyed ranged from 0 to 7 , with median (and interquartile range-IQR) of 2 (0, 2). None of the hospitals surveyed had a formal ASP or a policy on antibiotic restrictions (Figure 2 ). Three (25\%) hospitals routinely monitored antibiotic consumption and had an antibiotic use policy, while four (33.3\%) had a protocol for management of IDs in various departments. Although, 6 (50\%) hospitals reported routine monitoring of antibiotic resistance patterns, only one (8.3\%) routinely monitored specific AMRO such as ESBL, MRSA and CRE (Figure 2). Only one hospital (UNTH) had above average ASP score (58.3\%). All other hospitals had poor ASP score (between 0 to $33.3 \%$ ).

Of the 1324 participants, 417 (31.5\%) reported participating in a prior training on antibiotic use and resistance.

Figure 2: Implementation of antimicrobial stewardship programs and strategies by tertiary hospitals in Nigeria.

Figure legend

None of the hospitals had a formal ASP or policy on antibiotic restriction. Half (50\%) of the hospitals routinely monitored local AMR patterns. Abbreviation: UNTH-University of Nigeria Teaching Hospital, Enugu; AKTH- Aminu Kano University Teaching Hospital, Kano; NDUTH-Niger Delta University Teaching Hospital, Bayelsa; UCH-University College Hospital, Oyo State; LUTH-Lagos University Teaching Hospital, Lagos; UCTH-University of Calabar Teaching Hospital; UATH-University of Abuja Teaching Hospital

\section{Knowledge, attitude and practice of antibiotic use and resistance}

The majority (>80\%) of study participants had heard of rational antibiotic prescription and AMR, but only $40.6 \%$ had heard of ASP (Table 2 ). Awareness of antibiotic resistant organisms ranged from $49 \%$ to $83 \%$. Regarding knowledge of rational antibiotic use, $85.4 \%$ knew that antibiotics should only be stopped after completion of recommended doses, but $51 \%$ did not know that parenteral antibiotics are not necessarily more effective than oral antibiotics. Although $90 \%$ of participants knew that widespread use of antibiotics could promote emergence of AMR, most participants did not know that AMR could arise from use of antibiotics in farming and animal husbandry and from poor practice of hand hygiene in hospitals. The participants had lower knowledge scores for rational use of antibiotics compared to awareness about antibiotic use and resistance, and knowledge of causes of AMR (Table 2).

Table 2: Knowledge of antibiotic prescriptions and antimicrobial resistance among physicians in Nigeria 


\begin{tabular}{|c|c|c|c|}
\hline & Knowledge questions & $\%$ Correct & \% Wrong \\
\hline \multirow[t]{2}{*}{ A } & Awareness of antibiotic use and resistance & & \\
\hline & Have you previously heard about any of the following? & & \\
\hline 1 & Rational antibiotic use & 89.6 & 10.4 \\
\hline 2 & Antibiotic resistance & 97.7 & 2.3 \\
\hline 3 & Antibiotic stewardship program & 40.6 & 59.4 \\
\hline 4 & Antibiogram & 45.3 & 54.7 \\
\hline 5 & Methicillin-resistant Staphylococcus aureus (MRSA) & 83.2 & 16.8 \\
\hline 6 & Vancomycin-resistant Staphylococcus aureus (VRSA) & 74.2 & 25.8 \\
\hline 7 & Extended spectrum beta-lactamases (ESBL) & 65.3 & 34.7 \\
\hline \multirow[t]{2}{*}{8} & Carbapenem-resistant Enterobacteriaceae (CRE) & 48.9 & 51.1 \\
\hline & Overall \% Correct- Median (IQR)=75 $(62.5,87.5)$ & & \\
\hline \multirow[t]{2}{*}{ B } & Knowledge of rational antibiotic use & & \\
\hline & Concerning antibiotic use which of the following statements are correct? & & \\
\hline 9 & Antibiotics should not be used to treat non-bacterial infections & 76.6 & 23.4 \\
\hline 10 & Antibiotics may be used to treat common cold & 71.5 & 28.5 \\
\hline 11 & Antibiotics should be avoided in cases of acute diarrhoea & 51.5 & 48.5 \\
\hline 12 & Antibiotics should be stopped as soon as patient symptoms resolve & 84.1 & 15.9 \\
\hline 13 & Antibiotics should only be stopped after completing recommended doses & 85.4 & 14.6 \\
\hline 14 & Parenteral antibiotics are more effective than oral antibiotics & 49 & 51 \\
\hline 15 & Prophylactic surgical antibiotic should be discontinued after 24 hours & 39.4 & 60.6 \\
\hline \multirow[t]{2}{*}{16} & Prophylactic surgical antibiotic should not be given for less than 3days & 47.1 & 52.9 \\
\hline & Overall \% Correct- Median (IQR) $=62.5(50,75)$ & & \\
\hline C & Knowledge of definition of AMR & & \\
\hline 17 & Antibiotic Resistance means the micro-organism is resistant to the antibiotic & 69.3 & 30.7 \\
\hline \multirow[t]{2}{*}{ D } & Knowledge of causes of AMR & & \\
\hline & The following are known to promote emergence of antibiotic resistance? & & \\
\hline 18 & Widespread use of antibiotics & 90 & 10 \\
\hline 19 & Use of broad-spectrum antibiotics & 56.6 & 43.4 \\
\hline 20 & Antibiotic use in animal husbandry & 41.5 & 58.5 \\
\hline 21 & Antibiotic use in farming & 39.7 & 60.3 \\
\hline 22 & Poor practice of hand hygiene in hospitals & 47.7 & 52.3 \\
\hline 23 & Prescribing parenteral antibiotics & 62.6 & 37.4 \\
\hline 24 & Lack of antibiotics prescribing guidelines & 91.8 & 8.2 \\
\hline 25 & Microbial mutations & 94.3 & 5.7 \\
\hline 26 & Premature interruption of antibiotics & 92.7 & 7.3 \\
\hline 27 & Use of antibiotics to treat common cold & 74.5 & 25.5 \\
\hline \multirow[t]{2}{*}{28} & Vaccination & 74.5 & 25.5 \\
\hline & Overall \% Correct- Median (IQR)=72.7 $(63.6,81.8)$ & & \\
\hline
\end{tabular}

Concerning attitude toward antibiotic use and resistance, majority of participants agreed that AMR is a serious public health issue in Nigeria and worldwide and could be a problem for their hospital (Table 3). However, about $79 \%$ disagreed that routine hand washing could prevent AMR, $50 \%$ agreed that pharmaceutical companies could influence their choice of antibiotic prescriptions, and $27.9 \%$ wrongly believed that antibiotic could be used to prevent bacterial infection in patients with upper respiratory tract infection (URTI) due to viruses. 
Table 3 shows that about $62 \%$ of participants sometimes prescribe antibiotics because they did not trust the available laboratory results, $43 \%$ have ever prescribed antibiotics for malaria and $28 \%$ sometimes prescribe antibiotics for common cold. About $78 \%$ of participants stated that they had rarely or never stopped antibiotics immediately patient symptoms resolve, and $29.5 \%$ had sometimes prescribe antibiotics based on recommendation of pharmaceutical companies.

Table 3: Attitude and Practice of antibiotic prescriptions and antimicrobial resistance among physicians in Nigeria

\begin{tabular}{|c|c|c|c|c|c|c|}
\hline Sn & Attitude & $\begin{array}{l}\text { Strongly } \\
\text { agree }\end{array}$ & Agree & Neutral & Disagree & $\begin{array}{l}\text { Strongly } \\
\text { disagree }\end{array}$ \\
\hline & & $\%$ & $\%$ & $\%$ & $\%$ & $\%$ \\
\hline 1 & Antibiotic resistance is a serious public health issue worldwide & 79.3 & 18.5 & 1.8 & 0.3 & 0.2 \\
\hline 2 & Antibiotic resistance is a serious public health issue in Nigeria & 82.0 & 16.3 & 1.1 & 0.2 & 0.4 \\
\hline 3 & Antibiotic resistance is a problem in other hospitals but not in our hospital & 1.3 & 2.2 & 6.4 & 46.8 & 43.3 \\
\hline 4 & Antibiotic could be used to prevent bacterial infection in patients with viral URTI & 6.6 & 20.4 & 12.3 & 29.6 & 31.2 \\
\hline 5 & Any patient with fever would benefit from antibiotic therapy & 1.8 & 6.3 & 9.1 & 43.8 & 38.9 \\
\hline 6 & $\begin{array}{l}\text { Prolonged use of broad-spectrum antibiotics is a risk factor for antibiotic } \\
\text { resistance }\end{array}$ & 42.9 & 38.9 & 7.0 & 7.4 & 3.8 \\
\hline 7 & $\begin{array}{l}\text { Patients may feel better if you prescribe antibiotics to satisfy their demands } \\
\text { and expectations }\end{array}$ & 4.3 & 22.3 & 17.9 & 29.8 & 25.7 \\
\hline 8 & $\begin{array}{l}\text { There is nothing I can do as a person to lower the risk of antibiotic resistance in } \\
\text { our hospital }\end{array}$ & 2.2 & 1.9 & 6.1 & 38.6 & 51.2 \\
\hline 9 & There is no risk of resistance if antibiotics are taken as prescribed & 21.1 & 32.4 & 20.4 & 17.6 & 8.5 \\
\hline 10 & Persons who have never taken antibiotics have no risk of resistance & 8.0 & 19.1 & 10.1 & 46.1 & 16.8 \\
\hline 11 & It is better to stop antibiotics as soon as a patient feels better & 3.5 & 11.3 & 11.5 & 49.7 & 24.0 \\
\hline 12 & Regular hand washing can prevent antibiotics resistance & 4.6 & 7.9 & 8.3 & 42.6 & 36.6 \\
\hline 13 & $\begin{array}{l}\text { A longer course of antibiotic is less likely to cause resistance than a short } \\
\text { course }\end{array}$ & 7.8 & 19.2 & 18.6 & 37.7 & 16.7 \\
\hline 14 & Pharmaceutical companies sometimes influence my choice of antibiotics & 9.1 & 40.5 & 15.2 & 24.0 & 11.2 \\
\hline \multirow[t]{3}{*}{15} & $\begin{array}{l}\text { In hospital setting, antibiotic resistance could be transmitted from healthcare } \\
\text { worker to patients }\end{array}$ & 26.7 & 37.2 & 12.0 & 15.2 & 8.9 \\
\hline & Practice & Always & $\begin{array}{l}\text { Most of the } \\
\text { time }\end{array}$ & Sometimes & Rarely & Never \\
\hline & & $\%$ & $\%$ & $\%$ & $\%$ & $\%$ \\
\hline 1 & Prescribe antibiotics for common cold & 1.4 & 3.3 & 28.0 & 44.1 & 23.2 \\
\hline 2 & Prescribe antibiotics for pneumonia & 45.4 & 45.1 & 6.3 & 1.5 & 1.7 \\
\hline 3 & Prescribe antibiotics for malaria & 2.0 & 1.5 & 8.1 & 21.7 & 66.7 \\
\hline 4 & Stop antibiotics immediately patient symptoms resolve & 1.4 & 5.0 & 15.8 & 26.5 & 51.4 \\
\hline 5 & Prescribe antibiotics because patient insists on it & 0.2 & 0.8 & 11.2 & 27.8 & 60.0 \\
\hline 6 & Prescribe antibiotics because you do not trust the available laboratory results & 1.1 & 8.6 & 61.9 & 17.4 & 10.9 \\
\hline 7 & Wait for culture result before prescribing antibiotics & 0.8 & 10.6 & 49.2 & 30.5 & 8.9 \\
\hline 8 & Prescribe antibiotics based on culture results & 17.9 & 48.0 & 28.7 & 3.8 & 1.6 \\
\hline 9 & Prescribe antibiotic based on recommendation of pharmaceutical companies & 1.4 & 4.8 & 29.5 & 37.7 & 26.6 \\
\hline 10 & $\begin{array}{l}\text { Prescribe antibiotics inappropriately because patient cannot afford the } \\
\text { appropriate antibiotic }\end{array}$ & 0.4 & 3.4 & 34.0 & 29.0 & 33.2 \\
\hline 11 & $\begin{array}{l}\text { Prescribe antibiotics inappropriately because the appropriate antibiotic is not } \\
\text { available }\end{array}$ & 0.6 & 3.4 & 38.1 & 30.2 & 27.8 \\
\hline 12 & $\begin{array}{l}\text { De-escalate from broad spectrum to narrow spectrum antibiotics as soon as } \\
\text { culture results are available }\end{array}$ & 24.0 & 37.1 & 22.3 & 9.9 & 6.7 \\
\hline 13 & Prescribe prophylaxis antibiotics for more than 24 hours & 6.4 & 19.2 & 41.9 & 23.3 & 9.1 \\
\hline
\end{tabular}


All study participants (100\%) had prescribed one or more antibiotics in the previous 6 months. A median prescription of 15 antibiotics (IQR-13, 17) were prescribed per study participant in the previous 6 months. The prescription scores ranged from 20 to 90 with median (IQR) of 48 (43, 53). Amoxicillinclavulanate (98\%), ciprofloxacin/ofloxacin (97\%), ceftriaxone (96.8\%) and metronidazole (96.5\%) were the most frequently prescribed antibiotics (Figure 3). According to AWaRe categories, $100 \%, 99.3 \%, 67.8 \%$ of respondents had prescribed antibiotics from the Access, Watch and Reserve group of antibiotics, respectively.

Respondents practicing in FMC Nguru, Yobe State and AKTH, Kano and those working in Paediatrics and Internal Medicine departments reported higher rates of prescriptions of Cefepime than respondents from other hospitals and departments (Figure 4)

Figure 3: Frequency of prescription of various antibiotics by physicians in Nigeria in the prior six months.

Figure legend

Penicillins with $\beta$-lactamase inhibitors, fluoroquinolones and third generation cephalosporins were the most frequently classes of antibiotics prescribed. $68.6 \%$ had prescribed the Reserved antibiotic Cefepime.

Figure 4. Frequency of prescription of reserve antibiotic (Cefepime) among physicians in Nigeria

Figure legend

There was significant difference in prescription of Cefepime in relation to hospital of practice* and department of practicet. Physicians practicing in AKTH (92.5\%), FMCN (85.9\%) and UATH (85.7\%), all located in northern Nigeria, had the highest rates prescriptions of Cefepime. The highest rates of prescription of Cefepime were also observed among physicians practicing in and Internal Medicine (77.6\%) and Paediatrics (72.8\%) departments.

Abbreviations: UNTH-University of Nigeria Teaching Hospital, Enugu; AKTH- Aminu Kano University Teaching Hospital, Kano; NDUTH-Niger Delta University Teaching Hospital, Bayelsa; UCH-University College Hospital, Oyo State; LUTH-Lagos University Teaching Hospital, Lagos; UCTH-University of Calabar Teaching Hospital; UATH-University of Abuja Teaching Hospital; FMCN-Federal Medical Centre, Nguru, Yobe; FMCY-Federal Medical Centre, Yenagoa, Bayelsa; FMCO- Federal Medical Centre, Owerri, Imo; FMCBK- Federal Medical Centre, Birnin Kudu, Jigawa; ABUTH-Ahmadu Bello University Teaching Hospital, Kaduna;

\section{Correlations between knowledge, attitude, practice, and prescription (KAPPr) scores}

The correlations between KAPPr scores are shown in table 4. There were weak positive correlations between knowledge, attitude, and practice scores, and weak negative correlations when prescriptions scores are compared with knowledge, attitude, and practice scores.

Table 4. Spearman rho's correlations between knowledge, attitude, practice, and prescription scores

\begin{tabular}{|lllll|}
\hline Scores & $\begin{array}{l}\text { Knowledge score }- \\
r(p \text { value })\end{array}$ & $\begin{array}{l}\text { Attitude score- } \\
r(p \text { value })\end{array}$ & $\begin{array}{l}\text { Practice score- } \\
r \text { (p value })\end{array}$ & $\begin{array}{l}\text { Prescription score- } \\
r \text { (p value })\end{array}$ \\
\hline Knowledge score & 1 & $0.360(<0.0001)$ & $0.191(<0.0001)$ & -0.074 \\
& & & & $(0.008)$ \\
\hline Attitude score & 0.360 & 1 & $0.296(<0.0001)$ & $-0.217(<0.0001)$ \\
& $(<0.0001)$ & & & $-0.192(<0.0001)$ \\
\hline Practice score & 0.191 & $0.296(<0.0001)$ & 1 & \\
\hline Prescription score & -0.074 & & & \\
\hline & $(0.008)$ & $-0.217(<0.0001)$ & $-0.192(<0.0001)$ & 1 \\
\hline
\end{tabular}

NB: there were weak positive correlations between knowledge, attitude and practice scores and weak negative correlations between when prescription scores where compared with knowledge, attitude, and practice scores

\section{Prevalence and factors associated with good knowledge, attitude, practice, and prescription.}

The descriptive statistics of KAPPr scores are summarized in Table 5. Of the 1324 study participants, 295 (22.3\%), 534 (40.3\%), 418 (31.6\%) and 420 (31.7\%) had good knowledge, attitude, practice, and prescription, respectively. The factors associated with good KAPPr on univariate and multivariate analysis are shown in Table 6 and 7, respectively. Professional rank was independently associated with good knowledge, attitude, and prescription but not with good practice. Senior physicians (consultants and resident doctors) were between 1.6 to 3.3 times more likely to have good KAPPr than house officers. Those who previously participated in any training on antibiotic use and resistance were 2.6 times more likely to have good knowledge than those without any prior training.

Department of practice was independently associated with good prescription, but not associated with good knowledge, attitude, and practice. Respondents practicing in Paediatrics departments were significantly less likely to have good prescription compared to respondents from other departments. Hospital of practice was independently associated with good KAPPr. Overall, respondents practicing in South West Hospitals (UCH and LUTH) were more likely to have 
good KAPPr than those respondents from other hospitals (Figure 5). Respondents practicing in FMCN and FMCBK, both located in northern Nigeria, generally had lowest rates of good KAPPr.

Table 5. Descriptive statistics of knowledge, attitude, practice, and prescription scores of physicians in Nigeria

\begin{tabular}{|lllllll|}
\hline Variable & Score & Score $(\mathrm{n})$ & Score $(\%)$ & Good Score & Average Score & Poor Score \\
& Range & Median (IQR) & Median $($ IQR) & $\mathrm{n}(\%)$ & $\mathrm{n}(\%)$ & $\mathrm{n}(\%)$ \\
\hline Knowledge & $0-28$ & $19(16,21)$ & $71.1(62,79)$ & $293(22.3)$ & $963(73.4)$ & $56(4.3)$ \\
\hline Attitude & $15-75$ & $57(52,62)$ & $77(72,83)$ & $531(40.3)$ & $786(59.6)$ & $1(0.1)$ \\
Practice & $13-65$ & $49(46,52)$ & $75(72,80)$ & $416(31.6)$ & $899(68.4)$ & $0(0)$ \\
\hline Prescription & $18-90$ & $48(43,53)$ & $53.3(47.8,58.9)$ & $420(31.7)$ & $896(67.7)$ & $8(0.6)$ \\
\hline
\end{tabular}

Key: n-number of participants; IQR-interquartile range

Figure 5. Differences in prevalence of good knowledge, attitude, practice, and prescription in relation to hospital of practice of physicians in Nigeria.

Figure legend

LUTH and UCH both located in South-West Nigeria generally had higher prevalence of good KAPPr than other hospitals. Abbreviations: UNTH-University of Nigeria Teaching Hospital, Enugu; AKTH- Aminu Kano University Teaching Hospital, Kano; NDUTH-Niger Delta University Teaching Hospital, Bayelsa; UCHUniversity College Hospital, Oyo State; LUTH-Lagos University Teaching Hospital, Lagos; UCTH-University of Calabar Teaching Hospital; UATH-University of Abuja Teaching Hospital; FMCN-Federal Medical Centre, Nguru, Yobe; FMCY-Federal Medical Centre, Yenagoa, Bayelsa; FMCO- Federal Medical Centre, Owerri, Imo; FMCBK- Federal Medical Centre, Birnin Kudu, Jigawa; ABUTH-Ahmadu Bello University Teaching Hospital, Kaduna;

Table 6. Univariate analysis of factors associated with good knowledge, attitude, practice, and prescription among physicians in Nigeria 


\begin{tabular}{|c|c|c|c|c|c|}
\hline Variable & $\mathbf{N}$ & Good knowledge & Good attitude & Good practice & Good prescription \\
\hline & & $\mathrm{n}(\%)$ & n (\%) & $\mathrm{n}(\%)$ & n (\%) \\
\hline \multicolumn{6}{|l|}{ Gender } \\
\hline Female & 430 & $84(19.8)$ & $177(41.5)$ & $138(32.5)$ & $149(34.7)$ \\
\hline Male & 889 & $208(23.6)$ & $353(39.8)$ & 277 (31.3) & $268(30.1)$ \\
\hline \multicolumn{6}{|l|}{ Age group } \\
\hline$<36 y r s$ & 817 & $146(18.1) \dagger$ & $298(36.7) \dagger$ & $238(29.4) \dagger$ & $244(29.9)$ \\
\hline $36-49 y r s$ & 456 & $128(28.1)$ & $206(45.3)$ & $151(33.3)$ & $160(35.1)$ \\
\hline$>49 y r s$ & 51 & 19 (37.3) & $27(52.9)$ & $27(52.9)$ & $16(31.4)$ \\
\hline \multicolumn{6}{|l|}{ Professional rank } \\
\hline House officers & 268 & $33(12.5)$ * & $71(26.9)$ * & $69(26.2)$ * & $61(22.8)$ \\
\hline Medical officers/Residents & 879 & $197(22.6)$ & $362(41.2)$ & $290(33.1)$ & $280(31.9)$ \\
\hline Consultants & 177 & $63(35.6)$ & $98(55.7)$ & $57(32.4)$ & $79(44.6)$ \\
\hline \multicolumn{6}{|l|}{ Prior AMR training } \\
\hline No & 870 & $142(16.5)$ * & $323(37.3)+$ & $257(29.8) 9$ & $279(32.1)$ \\
\hline Yes & 417 & $143(34.5)$ & $190(45.7)$ & $147(35.3)$ & $132(31.7)$ \\
\hline \multicolumn{6}{|l|}{ Department } \\
\hline Paediatrics & 132 & $30(22.9) \dagger$ & $54(41.2)$ & $38(29)$ * & $23(17.4) 9$ \\
\hline Internal Medicine & 259 & $75(29)$ & $121(46.9)$ & $81(31.5)$ & 77 (29.7) \\
\hline O\&G & 515 & $105(20.5)$ & $197(38.5)$ & $150(29.5)$ & $161(31.3)$ \\
\hline Surgery & 164 & $42(25.8)$ & $67(41.1)$ & $58(35.4)$ & $60(36.6)$ \\
\hline Family Medicine & 80 & $14(18.2)$ & $25(31.2)$ & 39 (48.8) & $22(27.5)$ \\
\hline Others & 174 & $27(15.9)$ & $67(38.5)$ & $50(28.7)$ & $77(44.3)$ \\
\hline \multicolumn{6}{|l|}{ Hospital } \\
\hline LUTH & 123 & $50(40.7)$ * & $86(69.9)$ * & $52(42.3)$ * & $45(36.6)+$ \\
\hline $\mathrm{UCH}$ & 100 & 37 (37.4) & $51(52)$ & $40(40.8)$ & $47(47)$ \\
\hline UATH & 98 & $25(25.5)$ & $41(42.3)$ & $37(37.8)$ & $24(24.5)$ \\
\hline ABUTH & 235 & $48(20.4)$ & $103(43.8)$ & $63(26.9)$ & $80(34)$ \\
\hline FMCY & 83 & $13(16.2)$ & $18(21.7)$ & $33(39.8)$ & $24(28.9)$ \\
\hline NDUTH & 109 & $21(19.4)$ & $32(29.6)$ & $39(36.1)$ & 34 (31.2) \\
\hline UNTH & 88 & $12(13.6)$ & $23(26.1)$ & $13(15.1)$ & $25(28.4)$ \\
\hline AKTH & 107 & $29(28.2)$ & $45(42.1)$ & 19 (17.8) & $30(28)$ \\
\hline UCTH & 164 & $27(16.5)$ & $52(31.7)$ & $61(37.2)$ & $57(34.8)$ \\
\hline FMCO & 136 & 27 (20.3) & $62(46.3)$ & 42 (31.6) & 39 (28.7) \\
\hline FMCN & 38 & $2(5.3)$ & $7(18.4)$ & $9(23.7)$ & 5 (13.2) \\
\hline FMCBK & 43 & $2(4.7)$ & $11(25.6)$ & $8(18.6)$ & $10(23.3)$ \\
\hline All participants & 1324 & $293(22.3)$ & $531(40.3)$ & $416(31.6)$ & $420(31.7)$ \\
\hline
\end{tabular}

Key: $p<0.0001 *, p<0.001+, p<0.054 ; N$-number of participants; AMR-antimicrobial resistance

UNTH-University of Nigeria Teaching Hospital, Enugu; AKTH- Aminu Kano University Teaching Hospital, Kano; NDUTH-Niger Delta University Teaching Hospital, Bayelsa; UCH-University College Hospital, Oyo State; LUTH-Lagos University Teaching Hospital, Lagos; UCTH-University of Calabar Teaching Hospital; UATH-University of Abuja Teaching Hospital; FMCN-Federal Medical Centre, Nguru, Yobe; FMCY-Federal Medical Centre, Yenagoa, Bayelsa; FMCO- Federal Medical Centre, Owerri, Imo; FMCBK- Federal Medical Centre, Birnin Kudu, Jigawa; ABUTH-Ahmadu Bello University Teaching Hospital, Kaduna.

Table 7. Multivariate analysis of the predictors of good knowledge, attitude, practice, and prescription among physicians in Nigeria 


\begin{tabular}{|c|c|c|c|c|}
\hline Variable & Good Knowledge & Good Attitude & Good Practice & Good Prescription \\
\hline & AOR $(95 \% \mathrm{Cl})$ & AOR $(95 \% \mathrm{Cl})$ & AOR (95\% Cl) & AOR $(95 \% \mathrm{Cl})$ \\
\hline \multicolumn{5}{|l|}{ Gender } \\
\hline Female (Ref) & 1 & 1 & 1 & 1 \\
\hline Male & $1.5(1,2.1)$ & $1.1(0.9,1.5)$ & $1(0.8,1.4)$ & $0.8(0.6,1)$ \\
\hline \multicolumn{5}{|l|}{ Age group } \\
\hline <36years (Ref) & 1 & 1 & 1 & 1 \\
\hline 36-49years & $1.2(0.9,1.7)$ & $1(0.7,1.3)$ & $1.1(0.8,1.5)$ & $1(0.8,1.3)$ \\
\hline >49years & $1.7(0.8,3.5)$ & $1.2(0.6,2.4)$ & $2.7^{b}(1.4,5.4)$ & $0.6(0.3,1.1)$ \\
\hline \multicolumn{5}{|l|}{ Professional Category } \\
\hline House officers & 19 & $1 *$ & 1 & $1 *$ \\
\hline Medical officers/Residents & $1.69(1,2.5)$ & $1.8^{\mathrm{b}}(1.2,2.5)$ & $1.4(1,2)$ & $1.69(1.1,2.3)$ \\
\hline Consultants & $2.49(1.3,4.5)$ & $3^{c}(1.8,5)$ & $1(0.6,1.7)$ & $3.3^{c}(2,5.7)$ \\
\hline \multicolumn{5}{|l|}{ Prior AMR training } \\
\hline No (Ref) & $1 *$ & 1 & 1 & 1 \\
\hline Yes & $2.6(1.9,3.4)$ & $1.3(1,1.7)$ & $1.2(0.9,1.5)$ & $0.9(0.7,1.2)$ \\
\hline \multicolumn{5}{|l|}{ Department } \\
\hline Paediatrics (Ref) & 1 & 1 & 1 & $1 *$ \\
\hline Internal Medicine & $1.3(0.7,2.2)$ & $1.2(0.7,2)$ & $1.3(0.8,2.1)$ & $2.2^{\mathrm{b}}(1.3,3.9)$ \\
\hline$O \& G$ & $1.1(0.6,1.9)$ & $0.8(0.5,1.3)$ & $1.2(0.7,1.9)$ & $2.7^{c}(1.6,4.6)$ \\
\hline Surgery & $0.9(0.5,1.6)$ & $0.8(0.5,1.4)$ & $1.3(0.8,2.2)$ & $2.9^{c}(1.6,5.2)$ \\
\hline Family Medicine & $0.7(0.3,1.5)$ & $0.6(0.3,1.1)$ & $2.3(1.2,4.2)$ & $1.9(0.9,3.8)$ \\
\hline Others & $0.6(0.3,1.2)$ & $0.8(0.5,1.3)$ & $1.1(0.7,1.9)$ & $4.5^{\mathrm{c}}(2.5,8)$ \\
\hline \multicolumn{5}{|l|}{ Hospital } \\
\hline LUTH (Ref) & $1 *$ & $1 *$ & $1 *$ & $1 \dagger$ \\
\hline $\mathrm{UCH}$ & $0.9(0.5,1.6)$ & $0.5+(0.3,0.9)$ & $0.8(0.5,1.4)$ & $1.89(1,3.2)$ \\
\hline UATH & $0.5(0.3,1)$ & $0.4+(0.2,0.7)$ & $0.8(0.4,1.4)$ & $0.7(0.4,1.4)$ \\
\hline ABUTH & $0.4+(0.2,0.7)$ & $0.3^{*}(0.2,0.6)$ & $0.5+(0.3,0.8)$ & $0.8(0.5,1.3)$ \\
\hline FMCY & $0.3+(0.1,0.6)$ & $0.1 *(0.1,0.2)$ & $0.7(0.4,1.4)$ & $0.9(0.5,1.8)$ \\
\hline NDUTH & $0.3+(0.2,0.6)$ & $0.2^{\star}(0.1,0.4)$ & $0.7(0.4,1.3)$ & $1(0.6,1.9)$ \\
\hline UNTH & $0.2+(0.1,0.5)$ & $0.2^{\star}(0.1,0.4)$ & $0.3+(0.1,0.6)$ & $0.7(0.4,1.4)$ \\
\hline AKTH & $0.6(0.3,1.1)$ & $0.3^{*}(0.2,0.5)$ & $0.3+(0.2,0.6)$ & $0.6(0.3,1.1)$ \\
\hline UCTH & $0.3^{*}(0.2,0.6)$ & $0.2 *(0.1,0.4)$ & $0.8(0.5,1.4)$ & $1.2(0.7,2)$ \\
\hline FMCO & $0.3+(0.2,0.7)$ & $0.5+(0.3,0.9)$ & $0.7(0.4,1.2)$ & $0.8(0.4,1.4)$ \\
\hline FMCN & $0.1+(0,0.4)$ & $0.1 *(0,0.3)$ & $0.4(0.2,1)$ & $0.3(0.1,1)$ \\
\hline FMCBK & $0.1 *(0,0.3)$ & $0.1 *(0.1,0.3)$ & $0.3+(0.1,0.7)$ & $0.5(0.2,1.2)$ \\
\hline
\end{tabular}

Key: $p<0.000{ }^{\star}, p<0.001+, p<0.054$; Ref-reference group; AOR-adjusted odds ratio; Cl-Confidence Interval; AMR-antimicrobial resistance

UNTH-University of Nigeria Teaching Hospital, Enugu; AKTH- Aminu Kano University Teaching Hospital, Kano; NDUTH-Niger Delta University Teaching Hospital, Bayelsa; UCH-University College Hospital, Oyo State; LUTH-Lagos University Teaching Hospital, Lagos; UCTH-University of Calabar Teaching Hospital; UATH-University of Abuja Teaching Hospital; FMCN-Federal Medical Centre, Nguru, Yobe; FMCY-Federal Medical Centre, Yenagoa, Bayelsa; FMCO- Federal Medical Centre, Owerri, Imo; FMCBK- Federal Medical Centre, Birnin Kudu, Jigawa; ABUTH-Ahmadu Bello University Teaching Hospital, Kaduna;

\section{Discussion}


To the best of our knowledge, this is the first study from Nigeria assessing both implementation of ASM among tertiary hospitals and predictors of good KAP of APR and AMR among physicians practicing in all six geopolitical zones of Nigeria.

Our results suggest significant gaps in the implementation of antimicrobial stewardship (AMS), as none of the hospitals surveyed had a formal ASP program, while between $50 \%$ to $92 \%$ of participating hospitals were not routinely implementing one or more of the ASM-related interventions. There was also poor awareness of ASM, as only $41 \%$ of our respondents had previously heard of the term "Antimicrobial Stewardship Programme" as compared to awareness of rational use of antibiotics and AMR which were about $80 \%$ each. Poor compliance with AMS was reported by another study from Nigeria where only six (35\%) of 17 tertiary hospitals surveyed had a formal ASP and less than $23.5 \%$ of these hospitals implemented AMS-related interventions and policies.[15] A nationwide survey of pharmacist's involvement in ASP in Nigeria, revealed that only 5 (13.5\%) of 37 hospitals had a formal ASP. In a study evaluating physicians' knowledge and perception of AMS and AMR in six hospitals in three geopolitical zones of Nigeria, only $28.2 \%$ of respondents had ever heard of ASP and more respondents had good knowledge of AMR than ASP (82.7\% versus 36.5\%)[17].

Overall, our study data and other published literature from Nigeria suggest poor implementation of AMS-related interventions and policies among tertiary hospitals in the country. Similar findings have been reported in other countries in Africa. For instance, in an international survey of ASP in 660 hospitals across the globe, only $14 \%$ of 43 hospitals in Africa had an ASP in place as compared to 53\% (26/49), 66\% (230/348) and 66\% (45/67) of hospitals in Asia, Europe, and North America, respectively.[24] This international survey reported lack of funding and personnel, a lack of information technology, prescriber opposition and lack of awareness on the part of the hospital administration as perceived barriers to the implementation of ASP among countries surveyed. Other identified challenges to implementation of ASP in developing countries include, limited diagnostic infrastructure, poor access to quality-assured antimicrobials, and gaps in antibiotic prescribing and AMR-related knowledge and attitude among prescribers.[25,26] Although, the outcomes and impact of implementation of ASP have not been widely studied in Africa, few studies from this region suggest that African countries can successfully implement these programmes. [27]

We evaluated the KAP of APR and AMR among physicians in Nigeria to identify knowledge gaps, as well as behaviors and practices associated with APR and AMR among respondents. Respondents had better knowledge of AMR (median score of 72.7\%) than knowledge of rational APR (median score of $62.5 \%$ ). Most respondents agreed that AMR is a serious problem in their various hospitals and Nigeria as a whole. However, over half of our respondents did not know that AMR could arise from antibiotic use in animal husbandry and farming, and from poor practice of IPC in hospital settings. The gap in knowledge of the link between poor practice of IPC and AMR may partly explain why $79 \%$ of respondents disagreed that routine hand washing could prevent AMR and $36 \%$ were neutral or disagreed that AMR could be transmitted from healthcare worker to patient. About $83 \%$ of physicians in another study from Nigeria identified poor infection control as a possible cause of emergence of AMR in hospital settings.[17] However, this study did not specifically evaluate hand hygiene-related knowledge and attitude. Garba et al reported that $54.1 \%$ of healthcare workers in primary healthcare centers in Kaduna North local government area of northern Nigeria wrongly believed that practice of hand hygiene for prevention of AMR is overrated.[28] A study from Europe reported that junior doctors rarely perceived poor hand hygiene practices as important drivers of AMR.[29] The slogan 'Fight antibiotic resistance - it's in your hands' was formulated in 2017 by the WHO to emphasize the central role of hand hygiene in the prevention of AMR.[30] Our study findings suggest that there is need to improve awareness among physicians in Nigeria about the importance of practice of hand hygiene in reducing the transmission of AMRO in hospital settings.

The median KAP scores of respondents in our study were $71 \%, 75 \%$ and $77 \%$ respectively. However, only $22.3 \%$, $40.3 \%$, and 31.6 had good KAP (defined as score of $80 \%$ or above) of APR and AMR, respectively. In a systematic review of KAP of APR and AMR among healthcare practitioners from developing countries involving 15 studies (none from Nigeria) an average of $80.9 \%$ of respondents correctly answered questions relating to APR, whereas only $39.6 \%$ were aware of the local resistance patterns in their health facilities.[31] About $83 \%$ of physicians working in tertiary hospitals in four geopolitical zones of Nigeria were reported to have good knowledge of AMR (defined as knowledge score of $80 \%$ or above).[17] Among healthcare practitioners from primary health facilities in northern Nigeria, $73 \%$ had good knowledge of AMR (defined as knowledge score between $50 \%$ to $74 \%$ ), while less than $5 \%$ had very good knowledge of AMR (defined as knowledge score of 75\% and above).[32] The variability in the proportions of respondents with good knowledge from Nigeria could be related to differences in study design. It is our view that our study findings are representative of physicians in Nigeria as we included hospitals and physicians across all six geopolitical zones of the country.

Excessive and inappropriate prescription of antibiotics are established drivers of AMR.[33,34] Our results reveal that an average of 15 (83.3\%) of 18 antibiotics were prescribed by each respondent in the prior six months. About $69 \%$ of respondents were classified as having poor prescription practice, meaning they prescribed antibiotics inappropriately. Some indicators of inappropriate APR in our study included $43 \%$ of respondents ever prescribing antibiotics for malaria and $28 \%$ sometimes prescribing antibiotics for common cold. Our results also reveal some attitudes and drivers of irrational APR including influence of pharmaceutical companies, lack of trust in laboratory test results, attempting to satisfy patient expectations, prohibitive costs of some antibiotics, and limited access to appropriate antibiotic. Penicillins with $\beta$-lactamase inhibitors, fluoroquinolones and third generation cephalosporins were the most common classes of antibiotics frequently prescribed by respondents in our study. While most respondents had prescribed antibiotics from the WHO Access and Watch categories, it is remarkable that about $63 \%$ of respondents had prescribed antibiotics in the Reserve group of the WHO AWaRe categories. The high rates of prescription of the Reserve antibiotics Cefepime without recourse to culture results could ultimately lead to high burden of ESBL.

Many studies from Nigeria have also reported overuse and irrational prescription of antibiotics among physicians, with prevalence of self-reported APR ranging from $26.8 \%$ to $97 \%[17,18,35]$ and point prevalence surveys (PPS) reporting APR rates of $59.6 \%$ to $80.1 \%$ among in-patients. [36-39] The global PPS reported a higher prevalence of antibiotic prescribing among Africa hospitals (average of 50\%) compared to 27.4\% among European hospitals.[11]. Most of these studies also reported Penicillins with $\beta$-lactamase inhibitors, third generation cephalosporins and fluoroquinolones as the commonest classes of antibiotics prescribed. 
The determinants of inappropriate prescriptions of antibiotics have been reviewed by various authors.[40,41] A systematic review of physicians practicing in different settings across the globe identified patients' expectations, severity and duration of infections, uncertainty over diagnosis, potentially losing patients, and influence of pharmaceutical companies as drivers of irrational APR among physicians.[20] A study of physicians from a tertiary hospital in Lagos, Nigeria reported factors of cost, drug availability and pressure from pharmaceutical representatives as the major drivers of irrational APR among study participants. [18]

Educational programmes have been shown to improve awareness and knowledge of AMR among healthcare workers, as well as foster appropriate prescription behaviour.[42,43] We found that good knowledge of AMR and APR was associated with prior training on antibiotic use and resistance. However, the lack of association between prior training and good attitude, practice, and prescription, as well as the weak positive correlations between KAP, support the role of multiplicity of factors in determining attitudes and practices regarding APR and AMR.[35,44,45] Additional predictive factors observed in our study were professional rank, hospital and department of practice of physicians.

Independent of other variables, more senior physicians (consultants and resident doctors) in our study had better knowledge and attitudes, and prescribed antibiotics less frequently than recently qualified medical interns. Medical interns have limited experience of clinical practice, and it is not surprising they had the lowest KAPPr scores in our study. Besides poor knowledge, the more frequent prescriptions of antibiotics among these interns compared to other physicians could be related to the hierarchical nature of medical practice in Nigeria where medical interns are in most cases required to write out prescriptions based on instructions of their supervising residents or consultants. The rotation of interns through all major medical specialties has been shown to influence their prescription practice as they are made to transcribe prescriptions from a wide variety of their supervisors in the various departments.[46] Studies from Ghana[47], USA[48], Malaysia[49] and China[42] have also reported higher knowledge and less frequent prescriptions of antibiotic among senior physicians compared to junior physicians. Other studies have shown that prescription errors are more frequent among medical interns in hospital settings.[50,51]

Hospital of practice was independently associated with good KAPPr among physicians in our study. Physicians practicing in hospitals located in the SouthWest region of the country generally had better KAPPr scores than those from other hospitals. Prescriptions of Reserve antibiotic (Cefepime) were more frequently observed among physicians practicing in northern Nigeria, as all three hospitals with over $80 \%$ of physicians with prior prescriptions of Cefepime were in northern Nigeria. Among five published PPS from Nigeria[36,52-55], the lowest prevalence of antibiotic use among inpatients of 59.5\% was reported in a South-West hospital [54] while the highest prevalence of $80.1 \%$ was reported among three hospitals located in northern Nigeria.[37] The reasons for the observed hospital-based and regional differences in KAPPr scores and APR are not obvious from our study data, especially as there were no remarkable differences in the implementation of AMS between hospitals surveyed.

Variabilities between hospitals in APR and knowledge of AMR have also been reported by various other studies from other parts of the world [56,57] and they are usually fueled by contextual, cultural and behavioural factors that define the various hospitals. [58] Differences in the burden, types, and resistance patterns of ID between hospitals could determine the frequency and type of antibiotic prescribed. Organization culture may also influence how physicians prescribe.[59] Studies suggest that "prescribing etiquette" are usually created by senior physicians and passed on to junior physicians as part of mentorship process and to maintain the 'culture' of prescription within clinical groups. [46,60,61] Recognizing the importance of institutional context and peculiarities in the implementation of ASP, the WHO recommends institutional situational analysis and needs assessment before implementation of AMS in healthcare settings.[14]

Our study data show that physicians practicing in paediatric department prescribed antibiotics more frequently than those from other departments, and physicians practicing in internal medicine and paediatric were more likely to prescribe the Reserve antibiotic Cefepime than those in other departments. Several PPS suggest that paediatric departments rank second only to the intensive care unit with respect to antibiotic use in hospital settings. [36,52-55] These PPS have shown that APR are related to burden and resistance spectrum of bacterial infections among in-patients. Consequently, the observed variabilities of APR in relation to department of practice in our study could partly be due to higher burden of bacterial infections and AMR among patients in these departments. It could also be due to 'prescription etiquette' that favour more frequent APR in these departments.

Our study had several limitations. First, we did not evaluate all aspects of AMS in healthcare facilities as defined by the WHO.[14] However, our results identified fundamental gaps in the implementation of AMS in Nigeria tertiary hospitals deserving corrective interventions. Second, we did not use probability sampling in selecting respondents, and we could only enroll a limited number of respondents from the north-east region of the country due to prevailing security challenges in this region. However, our study is the first on KAP of AMR to include participants from all six geopolitical zones of the country. In view of the large sample size including participants from most parts of the country, we believe our sample is largely representative of the Nigeria context. Third, our study was not specifically designed to evaluate predictors of institutional or regional variabilities in good KAPPr. Future studies are necessary to determine other relevant contextual, cultural and behavioural factors that could influence KAP of antibiotic prescriptions among physicians in Nigeria.

In conclusion, our study results suggest a lack of implementation of AMS among tertiary hospitals in Nigeria. Although most physicians working in these hospitals had above average KAP of APR and AMR, there were gaps in knowledge and attitude and frequent prescriptions of antibiotics, including those in the Reserve group. Good KAPPr were associated with institutional, geographical, educational, and professional factors. Our study findings should inform interventions that optimize the use of antibiotics in healthcare facilities and improve awareness and understanding of AMR in Nigeria in line with Nigeria's NAPAR.

\section{Abbreviations}

AMR: Antimicrobial resistance

AMRO: Antimicrobial resistant organisms 
APR: Antibiotic prescription rate

ASP: Antibiotic stewardship programme

AMS: Antimicrobial stewardship

AWaRe: Access, Watch and Reserve categories

FCT: Federal Capital Territory

GAP: Global Action Plan

KAPPr: Knowledge, attitude, practice, and prescription

NAPAR: National action plan on antimicrobial resistance

PPS: Point prevalence surveys

Pr: Prescription

WHA: World Health Assembly

WHO: World Health Organization.

\section{Declarations}

\section{Ethics approval and consent to participate.}

All potential participants who agreed to participate provided written consent before completion of questionnaire. The questionnaire was anonymized, and confidentiality of information obtained was maintained. Ethical approval for the study was obtained from National Health Research Ethics Committee (NHREC/01/01/2017).

\section{Availability of data and materials}

The datasets in the present study are accessible from the corresponding author on reasonable request.

\section{Competing interests}

The authors declare that they have no competing interests.

\section{Funding}

The Nigeria Infectious Disease Society supported data entry and analysis.

\section{Authors' contributions}

DO, GI, AGH conceived the manuscript. DO analyzed the results and wrote the initial draft. All authors read and approved the final manuscript.

\section{Acknowledgements}

Not applicable

\section{References}

1. Aminov RI. A Brief History of the Antibiotic Era: Lessons Learned and Challenges for the Future. Front Microbiol 2010; 1. Available at: /pmc/articles/PMC3109405/?report=abstract. Accessed 23 December 2020.

2. Friedman ND, Temkin E, Carmeli Y. The negative impact of antibiotic resistance. Clin Microbiol Infect 2016; 22:416-422.

3. World Health Organisation. Antibiotic resistance. 2020. Available at: https://www.who.int/news-room/fact-sheets/detail/antibiotic-resistance. Accessed 23 December 2020.

4. Jim O'Neill. Antimicrobial Resistance: Tackling a crisis for the health and wealth of nations. 2014. Available at: https://amrreview.org/sites/default/files/AMR Review Paper - Tackling a crisis for the health and wealth of nations_1.pdf. Accessed 10 December 2020.

5. World Health Organisation. Global action plan on antimicrobial resistance. Geneva: World Health Organization, 2016. Available at: http://www.who.int/antimicrobial-resistance/global-action-plan/en/. Accessed 23 December 2020.

6. World Health Organisation. Report of the 21st WHO Expert Committee on the Selection and Use of Essential Medicines WHO headquarters, Geneva. 2017. Available at: http://www.who.int/selection_medicines/committees/subcommittee/2/eeb1098\%5B1\%5D.pdf. Accessed 5 December 2020.

7. National Population Commission (NPC) [Nigeria] and ICF International. Nigeria Demographic and Health Survey. 2018. Available at: https://www.nationalpopulation.gov.ng/ndhs-2018-key-finding/. 
8. Fedeal Ministeries of Agriculture Environment and Health. Antimicrobial use and resistance in Nigeria: situation analysis and recommendations, 2017. 2017. Available at: https://ncdc.gov.ng/themes/common/docs/protocols/56_1510840387.pdf.

9. Federal Ministries of Agriculture Environment and Health. National Action Plan for Antimicrobial Resistance. 2017. Available at: https://ncdc.gov.ng/themes/common/docs/protocols/77_1511368219.pdf. Accessed 7 November 2020.

10. Tadesse BT, Ashley EA, Ongarello S, et al. Antimicrobial resistance in Africa: A systematic review. BMC Infect Dis 2017; 17:1-17. Available at: http://www.crd.york.ac.uk/PROSPERO/myprospero.php. Accessed 24 December 2020.

11. Versporten A, Zarb P, Caniaux I, et al. Antimicrobial consumption and resistance in adult hospital inpatients in 53 countries: results of an internet-based global point prevalence survey. Lancet Glob Heal 2018; 6:e619-e629.

12. Mulvey MR, Simor AE. Antimicrobial resistance in hospitals: How concerned should we be? Can Med Assoc J 2009; 180:408-415. Available at: https://www.ncbi.nlm.nih.gov/pmc/articles/PMC2638041/. Accessed 24 December 2020.

13. Doron S, Davidson LE. Antimicrobial stewardship. Mayo Clin Proc 2011; 86:1113-1123. Available at: /pmc/articles/PMC3203003/?report=abstract. Accessed 13 December 2020.

14. World Health Organisation. Antimicrobial stewardship programmes in health-care facilities in low- and middle-income countries. A practical toolkit. Geneva: 2019.

15. Fadare JO, Ogunleye O, lliyasu G, et al. Status of antimicrobial stewardship programmes in Nigerian tertiary healthcare facilities: Findings and implications. J Glob Antimicrob Resist 2019; 17:132-136. Available at: https://pubmed.ncbi.nlm.nih.gov/30557686/. Accessed 26 October 2020.

16. Abubakar U, Tangiisuran B. Nationwide survey of pharmacists' involvement in antimicrobial stewardship programs in Nigerian tertiary hospitals. J Glob Antimicrob Resist 2020; 21:148-153. Available at: https://linkinghub.elsevier.com/retrieve/pii/S2213716519302619. Accessed 24 December 2020.

17. Babatola AO, Fadare JO, Olatunya OS, et al. Addressing antimicrobial resistance in Nigerian hospitals: exploring physicians prescribing behavior, knowledge, and perception of antimicrobial resistance and stewardship programs. Expert Rev Anti Infect Ther 2020; :1-10. Available at: https://pubmed.ncbi.nlm.nih.gov/32990480/. Accessed 26 October 2020.

18. Ogunleye OO, Fadare JO, Yinka-Ogunleye AF, Anand Paramadhas BD, Godman B. Determinants of antibiotic prescribing among doctors in a Nigerian urban tertiary hospital. Hosp Pract (1995) 2019; 47:53-58. Available at: https://pubmed.ncbi.nlm.nih.gov/29757036/. Accessed 26 October 2020.

19. Federal Ministry of Health. Nigeria Health Facility Registry. 2020. Available at: https://hfr.health.gov.ng/facilities/hospitals-search? _token=wCzs02E2GbOglxYPB4FckJ7D2EEvtyIVCoXzpya9\&state_id=1\&Iga_id=1\&ward_id=0\&facility_level_id=3\&ownership_id=1\&operational_status_id=1 i Accessed 24 December 2020.

20. Md Rezal RS, Hassali MA, Alrasheedy AA, Saleem F, Md Yusof FA, Godman B. Physicians' knowledge, perceptions and behaviour towards antibiotic prescribing: A systematic review of the literature. Expert Rev Anti Infect Ther 2015; 13:665-680. Available at: https://pubmed.ncbi.nlm.nih.gov/25813839/. Accessed 26 October 2020.

21. Teixeira Rodrigues A, Roque F, Falcão A, Figueiras A, Herdeiro MT. Understanding physician antibiotic prescribing behaviour: a systematic review of qualitative studies. Int J Antimicrob Agents 2013; 41:203-212. Available at: https://pubmed.ncbi.nlm.nih.gov/23127482/. Accessed 12 December 2020.

22. World Health Organisation. Antibiotic Resistance: Multi-country public awareness survey. 2015. Available at: www.who.int. Accessed 7 November 2020.

23. Bloom BS. Taxonomy of educational objectives, handbook I: The cognitive domain. New York: David McKay Co Inc, 1956.

24. Howard P, Pulcini C, Levy Hara G, et al. An international cross-sectional survey of antimicrobial stewardship programmes in hospitals. J Antimicrob Chemother 2014; 70:1245-1255.

25. Cox JA, Vlieghe E, Mendelson M, et al. Antibiotic stewardship in low- and middle-income countries: the same but different? Clin. Microbiol. Infect. 2017; 23:812-818. Available at: https://pubmed.ncbi.nlm.nih.gov/28712667/. Accessed 10 December 2020.

26. Pierce J, Apisarnthanarak A, Schellack N, et al. Global Antimicrobial Stewardship with a Focus on Low- and Middle-Income Countries. Int. J. Infect. Dis. 2020; 96:621-629.

27. Akpan MR, Isemin NU, Udoh AE, Ashiru-Oredope D. Implementation of antimicrobial stewardship programmes in African countries: a systematic literature review. J. Glob. Antimicrob. Resist. 2020; 22:317-324.

28. Garba, Giwa F, Abubakar AA. Knowledge of antibiotic resistance among healthcare workers in primary healthcare centers in Kaduna North local government area. Sub-Saharan African J Med 2020; 5:86. Available at: https://www.ssajm.org/article.asp?issn=23845147; year=2018; volume=5;issue=3; spage=86;epage=92;aulast=Garba. Accessed 11 December 2020.

29. Pulcini C, Williams F, Molinari N, Davey P, Nathwani D. Junior doctors' knowledge and perceptions of antibiotic resistance and prescribing: A survey in France and Scotland. Clin Microbiol Infect 2011; 17:80-87. Available at: www.onerba.org. Accessed 12 December 2020.

30. World Health Organisation. SAVE LIVES: Clean Your Hands 5 May 2017. World Health Organization, 2017. Available at: http://www.who.int/infectionprevention/campaigns/clean-hands/2017/en/. Accessed 11 December 2020.

31. Chaw PS, Höpner J, Mikolajczyk R. The knowledge, attitude and practice of health practitioners towards antibiotic prescribing and resistance in developing countries-A systematic review. J Clin Pharm Ther 2018; 43:606-613. Available at: https://onlinelibrary.wiley.com/doi/abs/10.1111/jcpt.12730. Accessed 24 November 2019.

32. Garba, Giwa F, Abubakar AA. Knowledge of antibiotic resistance among healthcare workers in primary healthcare centers in Kaduna North local government area. Sub-Saharan African J Med 2020; 5:86. Available at: https://www.ssajm.org/article.asp?issn=23845147; year=2018; volume=5;issue=3;spage=86;epage=92;aulast=Garba. Accessed 21 December 2020.

33. Bell BG, Schellevis F, Stobberingh E, Goossens H, Pringle M. A systematic review and meta-analysis of the effects of antibiotic consumption on antibiotic resistance. BMC Infect Dis 2014; 14:13. Available at: http://www.ncbi.nlm.nih.gov/pubmed/24405683. Accessed 12 October 2019.

Page $16 / 21$ 
34. Cantón R, Horcajada JP, Oliver A, Garbajosa PR, Vila J. Inappropriate use of antibiotics in hospitals: The complex relationship between antibiotic use and antimicrobial resistance. Enferm Infecc Microbiol Clin 2013; 31:3-11. Available at: https://pubmed.ncbi.nlm.nih.gov/24129283/. Accessed 23 December 2020.

35. Egwuenu A, Olayinka B, Apeji Y, et al. A systematic review on antibiotic use in humans in Nigeria. In: Pan African Medical Journal Conference Proceedings. Pan African Medical Journal, 2018. Available at: https://www.proceedings.panafrican-med-journal.com/conferences/2018/8/38/abstract/. Accessed 26 October 2020.

36. Oduyebo O, Olayinka A, Iregbu K, et al. A point prevalence survey of antimicrobial prescribing in four Nigerian Tertiary Hospitals. Ann Trop Pathol 2017; 8:42. Available at: http://www.atpjournal.org/text.asp?2017/8/1/42/224161. Accessed 4 December 2020.

37. Abubakar U. Antibiotic use among hospitalized patients in northern Nigeria: A multicenter point-prevalence survey. BMC Infect Dis 2020; 20:86. Available at: http://www.ncbi.nlm.nih.gov/pubmed/32000722. Accessed 26 October 2020.

38. Umeokonkwo CD, Madubueze UC, Onah CK, et al. Point prevalence survey of antimicrobial prescription in a tertiary hospital in South East Nigeria: A call for improved antibiotic stewardship. J Glob Antimicrob Resist 2019; 17:291-295. Available at: https://linkinghub.elsevier.com/retrieve/pii/S2213716519300207. Accessed 26 October 2020.

39. Fowotade A, Fasuyi T, Aigbovo O, et al. Point Prevalence Survey of Antimicrobial Prescribing in a Nigerian Hospital: Findings and Implications on Antimicrobial Resistance. West Afr J Med 2020; 37:216-220. Available at: https://pubmed.ncbi.nlm.nih.gov/32476113/. Accessed 15 December 2020.

40. Calbo E, Álvarez-Rocha L, Gudiol F, Pasquau J. A review of the factors influencing antimicrobial prescribing. Enferm Infecc Microbiol Clin 2013; $31: 12-15$. Available at: https://pubmed.ncbi.nlm.nih.gov/24129284/. Accessed 23 December 2020.

41. Tangcharoensathien V, Chanvatik S, Sommanustweechai A. Complex determinants of inappropriate use of antibiotics. Bull World Health Organ 2018; 96:141-144. Available at: https://www.ncbi.nlm.nih.gov/pmc/articles/PMC5791781/. Accessed 23 December 2020.

42. Liu C, Liu C, Wang D, Zhang X. Knowledge, Attitudes and Intentions to Prescribe Antibiotics: A Structural Equation Modeling Study of Primary Care Institutions in Hubei, China. Int J Environ Res Public Health 2019; 16:2385. Available at: https://www.mdpi.com/1660-4601/16/13/2385. Accessed 12 December 2020.

43. Roque F, Herdeiro MT, Soares S, Teixeira Rodrigues A, Breitenfeld L, Figueiras A. Educational interventions to improve prescription and dispensing of antibiotics: a systematic review. BMC Public Health 2014; 14:1276. Available at: /pmc/articles/PMC4302109/?report=abstract. Accessed 12 December 2020.

44. Dyar OJ, Beović B, Vlahović-Palčevski V, Verheij T, Pulcini C. How can we improve antibiotic prescribing in primary care? Expert Rev. Anti. Infect. Ther. 2016; 14:403-413. Available at: https://www.tandfonline.com/doi/abs/10.1586/14787210.2016.1151353. Accessed 12 December 2020.

45. Liu C, Liu C, Wang D, Zhang X. Intrinsic and external determinants of antibiotic prescribing: a multi-level path analysis of primary care prescriptions in Hubei, China. Antimicrob Resist Infect Control 2019; 8:132. Available at: https://aricjournal.biomedcentral.com/articles/10.1186/s13756-019-0592-5. Accessed 13 December 2020.

46. Lam TP, Chan TH, Sun KS, Lam KF, Kwok KW, Ho PL. Antibiotic prescriptions by medical interns in Hong Kong: influence of the hospital settings and prescription culture. Postgrad Med J 2020; :postgradmedj-2020-138414. Available at: https://pmj.bmj.com/content/early/2020/08/25/postgradmedj2020-138414. Accessed 21 December 2020.

47. Labi AK, Obeng-Nkrumah N, Bjerrum S, et al. Physicians' knowledge, attitudes, and perceptions concerning antibiotic resistance: A survey in a Ghanaian tertiary care hospital. BMC Health Serv Res 2018; 18:126. Available at: https://bmchealthservres.biomedcentral.com/articles/10.1186/s12913-018-2899y. Accessed 12 December 2020.

48. Srinivasan A, Song X, Richards A, Sinkowitz-Cochran R, Cardo D, Rand C. A Survey of Knowledge, Attitudes, and Beliefs of House Staff Physicians From Various Specialties Concerning Antimicrobial Use and Resistance. Arch Intern Med 2004; 164:1451. Available at: https://pubmed.ncbi.nlm.nih.gov/15249355/. Accessed 12 December 2020.

49. Leong TW, Rahmah S, Ishak S, Ali Z. Knowledge, attitude and practice of antibiotics prescribing among medical officers of public health care facilities in the state of Kedah, Malaysia. Med J Malaysia 2015; 70:307-311.

50. Dean B, Schachter M, Vincent C, Barber N. Prescribing errors in hospital inpatients: Their incidence and clinical significance. Qual Saf Heal Care 2002; 11:340-344. Available at: www.qualityhealthcare.com. Accessed 21 December 2020.

51. Ajemigbitse A, Ezike N, Erhun W, Omole M. Assessment of the knowledge and attitudes of intern doctors to medication prescribing errors in a Nigeria tertiary hospital. J Basic Clin Pharm 2014; 5:7. Available at: https://pubmed.ncbi.nlm.nih.gov/24808682/. Accessed 7 November 2020.

52. Abubakar U. Antibiotic use among hospitalized patients in northern Nigeria: a multicenter point-prevalence survey. BMC Infect Dis 2020; 20:86. Available at: https://pubmed.ncbi.nlm.nih.gov/32000722/. Accessed 26 October 2020.

53. Umeokonkwo CD, Madubueze UC, Onah CK, et al. Point prevalence survey of antimicrobial prescription in a tertiary hospital in South East Nigeria: A call for improved antibiotic stewardship. J Glob Antimicrob Resist 2019; 17:291-295. Available at: https://pubmed.ncbi.nlm.nih.gov/30668994/. Accessed 26 October 2020.

54. Fowotade A, Fasuyi T, Aigbovo O, et al. Point Prevalence Survey of Antimicrobial Prescribing in a Nigerian Hospital: Findings and Implications on Antimicrobial Resistance. West Afr J Med 2020; 37:216-220. Available at: https://pubmed.ncbi.nlm.nih.gov/32476113/. Accessed 26 October 2020.

55. Ekuma A, ljezie E, Akpabio T, Onwuezobe I. Survey of antimicrobial consumption in a university teaching hospital in Southern Nigeria. Ann Trop Pathol 2019; 10:48. Available at: http://www.atpjournal.org/text.asp?2019/10/1/48/258164. Accessed 20 December 2020.

56. Ghaffary S, Entezari-Maleki T, Abdollahpour J, Hamishehkar H. Measurement and comparison of inpatient antibiotic use in five different hospitals in Tabriz. Pharm Sci 2017; 23:37-41. 
57. Gerber JS, Newland JG, Coffin SE, et al. Variability in Antibiotic Use at Children's Hospitals. Pediatrics 2010; 126:1067-1073. Available at: http://pediatrics.aappublications.org/cgi/doi/10.1542/peds.2010-1275. Accessed 12 December 2020.

58. Hulscher ME, Grol RP, van der Meer JW. Antibiotic prescribing in hospitals: a social and behavioural scientific approach. Lancet Infect Dis 2010; 10:167175. Available at: www.thelancet.com/. Accessed 12 December 2020.

59. Machen S, Jani Y, Turner S, Marshall M, Fulop NJ. The role of organizational and professional cultures in medication safety: A scoping review of the literature. Int. J. Qual. Heal. Care. 2019; 31:G146-G157. Available at: https://pubmed.ncbi.nlm.nih.gov/31822887/. Accessed 13 December 2020.

60. De Souza V, MacFarlane A, Murphy AW, Hanahoe B, Barber A, Cormican M. A qualitative study of factors influencing antimicrobial prescribing by nonconsultant hospital doctors. J Antimicrob Chemother 2006; 58:840-843. Available at: https://pubmed.ncbi.nlm.nih.gov/16885179/. Accessed 20 December 2020.

61. Charani E, Castro-Sanchez E, Sevdalis N, et al. Understanding the determinants of antimicrobial prescribing within hospitals: The role of 'prescribing etiquette'. Clin Infect Dis 2013; 57:188-196. Available at: https://pubmed.ncbi.nlm.nih.gov/23572483/. Accessed 12 December 2020.

\section{Figures}

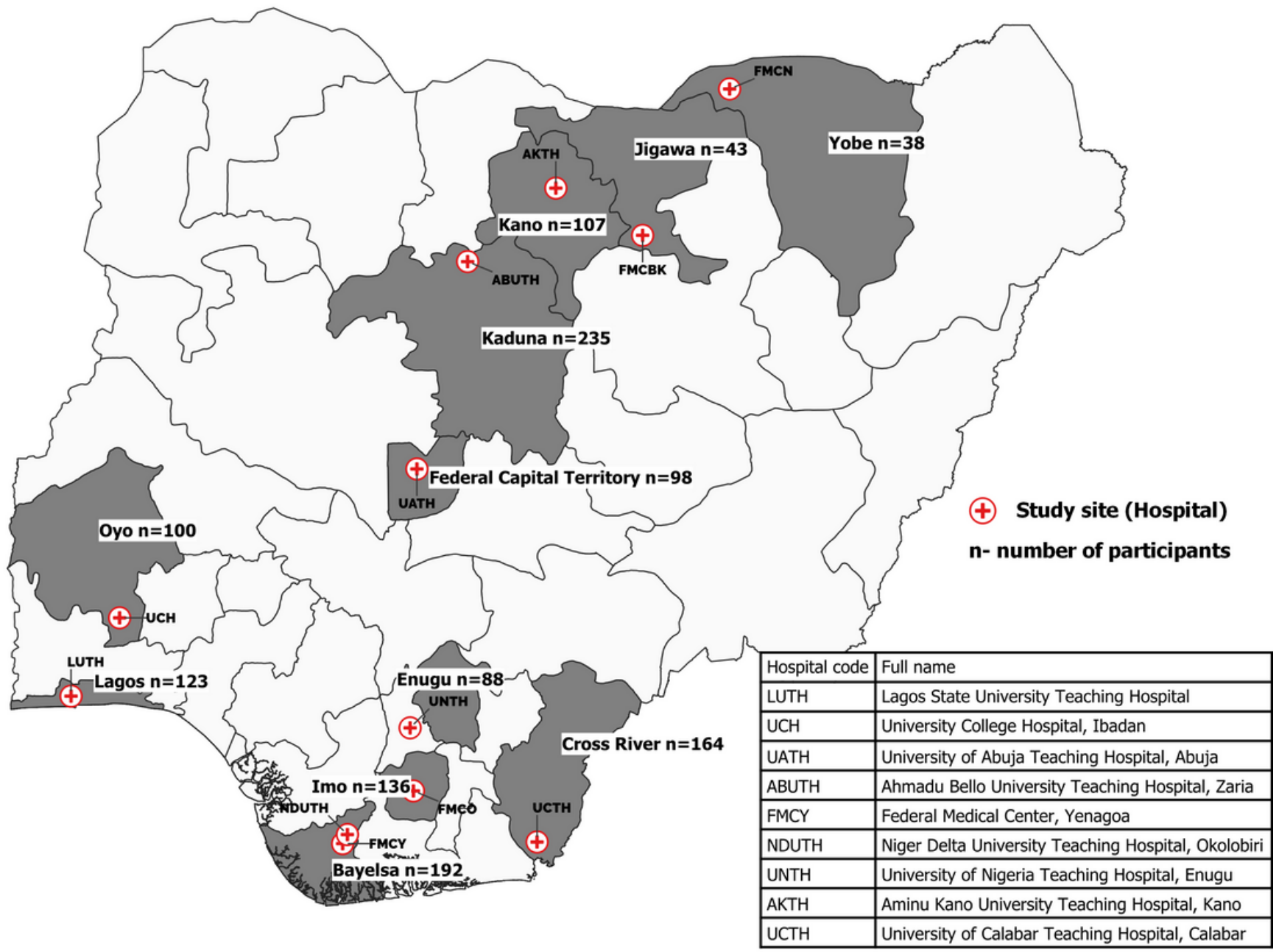

Figure 1

Geographical and hospital-based distribution of study participants. Note: The designations employed and the presentation of the material on this map do not imply the expression of any opinion whatsoever on the part of Research Square concerning the legal status of any country, territory, city or area o bbnhjr of its authorities, or concerning the delimitation of its frontiers or boundaries. This map has been provided by the authors. 
The hospital routinely monitors VRSA

The hospital has a policy on antibiotic restriction

The hospital has a formal antibiotic stewardship program

The hospital routinely monitors CRE

The hospital routinely monitors MRSA

The hospital routinely monitors ESBL

The hospital has a policy on surgical antibitoic prophylaxis

The hospital routinely audits antibiotic prescriptions

The hospital routinely monitors antibiotic consumption

The hospital has an antibiotic use policy or guideline

The hospital has a protocol for management of ID

The hospital routinely monitors local AMR patterns

\section{UNTH}

UNTH

UNTH

AKTH

UNTH

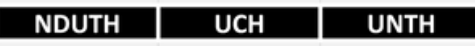

\begin{tabular}{|l|l|l|}
\hline AKTH & LUTH & UNTH \\
\hline
\end{tabular}

\begin{tabular}{|l|l|l|l|}
\hline AKTH & UATH & LUTH & UCTH \\
\hline
\end{tabular}

\begin{tabular}{l|l|l|l}
\hline AKTH & NDUTH & UATH & UCTH \\
\hline
\end{tabular}

1

2

3

4

4

UCH

UNTH

Number and names of hospitals implementing ASM-related policies or strategies

\section{Figure 2}

Implementation of antimicrobial stewardship programs and strategies by tertiary hospitals in Nigeria. Figure legend None of the hospitals had a formal ASP or policy on antibiotic restriction. Half (50\%) of the hospitals routinely monitored local AMR patterns. Abbreviation: UNTH-University of Nigeria Teaching Hospital, Enugu; AKTH- Aminu Kano University Teaching Hospital, Kano; NDUTH-Niger Delta University Teaching Hospital, Bayelsa; UCH-University College Hospital, Oyo State; LUTH-Lagos University Teaching Hospital, Lagos; UCTH-University of Calabar Teaching Hospital; UATH-University of Abuja Teaching Hospital

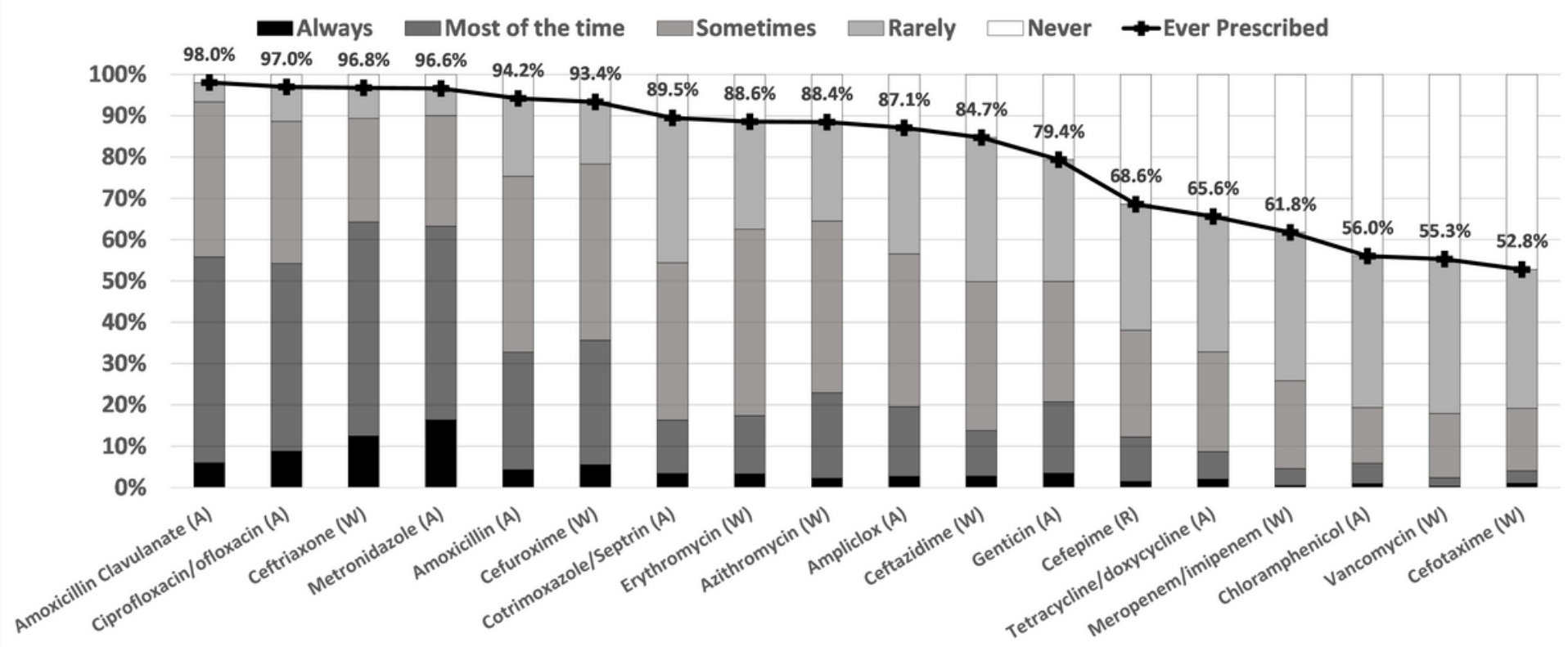

Name of antibiotic

\section{Figure 3}

Frequency of prescription of various antibiotics by physicians in Nigeria in the prior six months. Figure legend Penicillins with $\beta$-lactamase inhibitors, fluoroquinolones and third generation cephalosporins were the most frequently classes of antibiotics prescribed. $68.6 \%$ had prescribed the Reserved antibiotic Cefepime. 


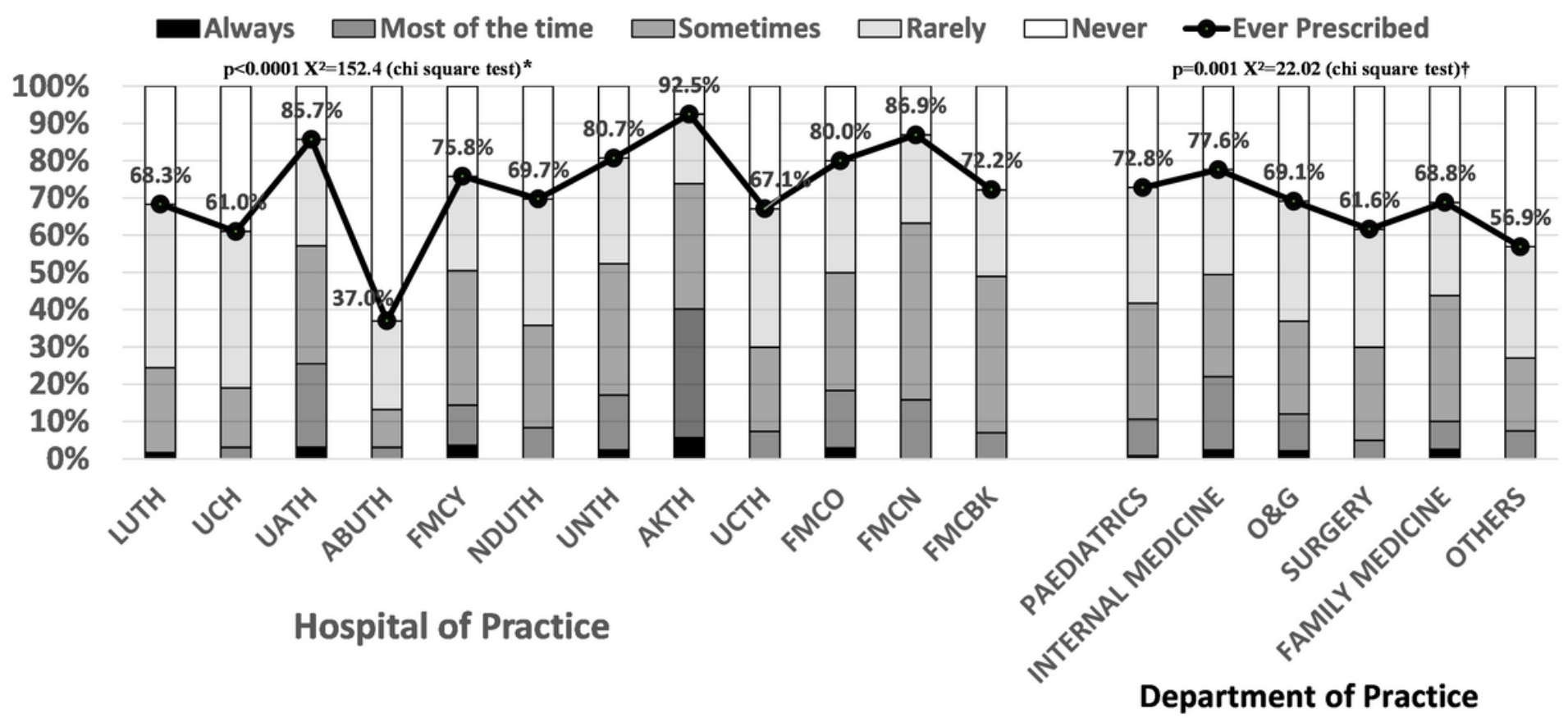

Figure 4

Frequency of prescription of reserve antibiotic (Cefepime) among physicians in Nigeria Figure legend There was significant difference in prescription of Cefepime in relation to hospital of practice* and department of practicet. Physicians practicing in AKTH (92.5\%), FMCN (85.9\%) and UATH (85.7\%), all located in northern Nigeria, had the highest rates prescriptions of Cefepime. The highest rates of prescription of Cefepime were also observed among physicians practicing in and Internal Medicine (77.6\%) and Paediatrics (72.8\%) departments. Abbreviations: UNTH-University of Nigeria Teaching Hospital, Enugu; AKTHAminu Kano University Teaching Hospital, Kano; NDUTH-Niger Delta University Teaching Hospital, Bayelsa; UCH-University College Hospital, Oyo State; LUTHLagos University Teaching Hospital, Lagos; UCTH-University of Calabar Teaching Hospital; UATH-University of Abuja Teaching Hospital; FMCN-Federal Medical Centre, Nguru, Yobe; FMCY-Federal Medical Centre, Yenagoa, Bayelsa; FMCO- Federal Medical Centre, Owerri, Imo; FMCBK- Federal Medical Centre, Birnin Kudu, Jigawa; ABUTH-Ahmadu Bello University Teaching Hospital, Kaduna;

$80 \%$

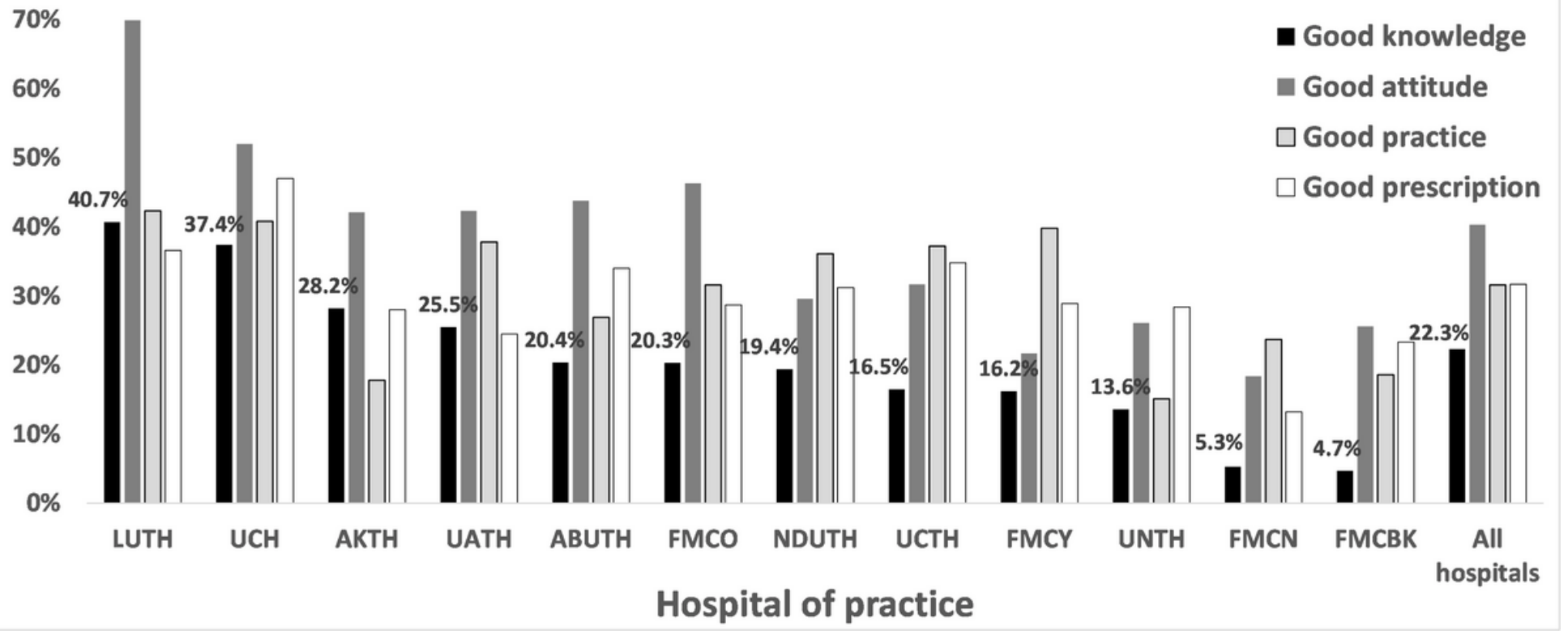

Figure 5

Differences in prevalence of good knowledge, attitude, practice, and prescription in relation to hospital of practice of physicians in Nigeria. Figure legend LUTH and UCH both located in South-West Nigeria generally had higher prevalence of good KAPPr than other hospitals. Abbreviations: UNTH-University of Nigeria Teaching Hospital, Enugu; AKTH- Aminu Kano University Teaching Hospital, Kano; NDUTH-Niger Delta University Teaching Hospital, Bayelsa; UCH-University 
College Hospital, Oyo State; LUTH-Lagos University Teaching Hospital, Lagos; UCTH-University of Calabar Teaching Hospital; UATH-University of Abuja Teaching Hospital; FMCN-Federal Medical Centre, Nguru, Yobe; FMCY-Federal Medical Centre, Yenagoa, Bayelsa; FMCO- Federal Medical Centre, Owerri, Imo; FMCBK- Federal Medical Centre, Birnin Kudu, Jigawa; ABUTH-Ahmadu Bello University Teaching Hospital, Kaduna; 